\title{
Selection of Cutting Inserts in Dry Machining for Reducing Energy Consumption and $\mathrm{CO}_{2}$ Emissions
}

\author{
Rosario Domingo ${ }^{1, *}$, Marta María Marín ${ }^{1}$, Juan Claver ${ }^{1}$ and Roque Calvo ${ }^{2}$ \\ Received: 22 August 2015 ; Accepted: 9 November 2015 ; Published: 18 November 2015 \\ Academic Editor: Mark Lemon \\ 1 Departamento de Ingeniería de Construcción y Fabricación, \\ Universidad Nacional de Educación a Distancia (UNED), C/Juan del Rosal 12, Madrid 28040, Spain; \\ mmarin@ind.uned.es (M.M.M.); jclaver@madrid.uned.es (J.C.) \\ 2 Departamento de Ingeniería Mecánica, Química y Diseño Industrial, Universidad Politécnica de Madrid, \\ Ronda de Valencia 3, Madrid 28012, Spain; roque.calvo@upm.es \\ * Correspondence: rdomingo@ind.uned.es; Tel.: +34-913-986-455; Fax: +34-913-986-046
}

\begin{abstract}
Manufacturing processes are responsible for climate change due to the emissions produced as result of energy consumption. This paper analyzes the influence of the cutting conditions and the characteristics of cutting tools on the energy required in machining processes and the carbon dioxide equivalent $\left(\mathrm{CO}_{2}\right.$-eq) emissions generated per material removed ratio (MRR) in an effort to define common criteria for using cutting inserts in a sustainable manner. Consequently, four cutting inserts were evaluated during the turning of Ti6Al4V alloy. An experimental and statistical methodology that combined the orthogonal array L36, the signal-to-noise ratio under the "small is better" criterion of Taguchi, and a multifactor analysis of variance was used. The effects of the geometry, material and coating of the tool and the cutting conditions on the energy and the carbon footprint during the manufacturing process were analyzed. The results show that a high tool cutting length and a high cutting depth are significant common factors, whereas the coating-cutting depth and cutting length-cutting speed are significant common interactions for both the energy/MRR ratio and the $\mathrm{CO}_{2}$-eq emissions/MRR ratio, and the coating-cutting speed exhibits a significant interaction for emissions. The outcomes show that the lifespan of the tool has little influence on the total emissions, at the time that the methodology is able to identify the most appropriate manner to calculate energy.
\end{abstract}

Keywords: carbon dioxide emissions; energy; sustainability; turning; Ti6Al4V; insert

\section{Introduction}

Intense industrial activity and manufacturing processes require high energy consumption and thereby the generation of greenhouse gas (GHG) emissions, which have negative consequences for the preservation of resources and the environment, due to their contribution to global warming. These GHG emissions include carbon dioxide $\left(\mathrm{CO}_{2}\right)$, the main contaminant gas generated in the world, and other gases such as methane, nitrous oxide and chlorofluorocarbons which can be measured in units of $\mathrm{CO}_{2}$ equivalents $\left(\mathrm{CO}_{2}\right.$-eq) [1]. In the manufacturing field, designs that reduce energy use and emissions are the main issues considered by companies in their attempt to move toward greater sustainability [2]. Energy efficiency is a current concern, and policies regarding it affect the environment because this efficiency can contribute to reducing emissions and favor decreasing the greenhouse effect [3]. Some companies have their own policies and focus their production on clean manufacturing [4] and models are being developed to minimize environmental impacts while maximizing resource efficiency in particular cases, such as gear manufacturing [5]. In the industrial field, where innovation is continuous, the influence of many factors (e.g., equipment, materials and 
tools) must be considered. New materials and new processes or modifications of old processes appear constantly in the search for high performance due to global competition.

Although processes are often studied by considering their energy consumption [6], it is convenient to investigate the GHG emissions generated by particular industrial activities. Problems attributed to $\mathrm{CO}_{2}$ emissions have been exposed in some products [7] due to their contribution to climate change. Recently, criticism has arisen regarding the suitability of GHG emission reductions due to their weak economic impacts [8], but some researchers have demonstrated that emissions reductions can be compatible with costs savings in a manufacturing plant through environmental innovation [9] and that the environmental commitment can improve the industrial plant's productivity [10]. These items are also inherent in mechanical manufacturing processes, in which machining is commonly used due to its versatility. Thus, in these processes, features such as machines, fixtures, tools and cutting fluids, including lubricants and coolants, should be studied because these affect the results of the operations performed. The equipment used in these processes, namely, machine tools, must be designed in a more efficient manner to survive in the market [11], but the current focus is on the process. For these reasons, machining processes that require material to be removed from an initial part must be thoroughly analyzed. These processes require greater power and higher energy causing high $\mathrm{CO}_{2}$-eq emissions, particularly for harder materials, where higher cutting speed is required. High performance also requires a high feed rate and high cutting depth because these allow faster material removal. For these reasons, some energy consumption models have been proposed [12], and different strategies for the design of tool paths have been studied [13] with the objective of consuming less energy in the process. Many efforts have been devoted to the study of cutting fluids and processes in dry [14] or cryogenic $[15,16]$ conditions, and these have yielded better results compared with wet machining. The tool is an important element because it is responsible for material removal; thus, tool design, including the geometry and the materials used, has been a priority in this field [17]. Consequently, tool design has evolved in recent decades but continues to focus on achieving higher performance without considering the sustainability of the process.

The titanium alloy Ti6Al4V is commonly used in the aeronautical and biomedical industries, among others, due to its good mechanical proprieties and its biocompatibility in medical uses. In the machining process, turning operations are utilized to obtain the final geometry of many components. The difficulty of machining is a common topic in the literature $[18,19]$. This alloy is very hard, and it is susceptible to temperature increments during machining, which can induce a phase change. Moreover, the thermal conductivity of this alloy is low compared to that of other materials, such as steel, which causes an increase in temperature in the machining zone. In general, titanium consumes more energy and produces more emissions than other structural materials, such as stainless steel; thus, its convenience of use must take into account the product lifespan [20]. This titanium alloy has been selected for this study due to its widespread use and the difficulties associated with its machining. In particular, for roughing operation, it is important from a sustainable perspective to determine the insert and the cutting conditions that would result in low energy consumption and $\mathrm{CO}_{2}$-eq emissions.

Dry machining is considered a more sustainable process than machining with cutting fluids due to the absence of lubricants and coolants, which results in a reduced use of resources [14,21]. Moreover, in the dry turning of titanium alloy, the cutting forces required are lower than those required using cutting fluids [18], and a better surface quality is achieved [19] than in wet machining. In this sense, the selection of a dry process could result in a reduction of energy consumption. However, dry machining results in higher wear of the cutting inserts [19], which can be counterweighted with the use of coating inserts to increase tool life [22].

Some strategies and models have been developed mainly to minimize the energy consumption in machining. Rajemi et al. [23] proposed a model that looks for the selection of the optimal turning conditions based on minimum energy considerations. Balogun and Mativenga [24] then improved 
the model to introduce direct energy requirements, and Peng et al. [25] developed an energy model implementation for future CNC machining systems based on function blocks. Iqbal et al. [26] established a set of rules utilizing fuzzy logic and found that a long tool life is associated with more energy consumption and low productivity. In addition, Schultheiss et al. [27] showed that it is possible to increase tool life through the use of worn tools in secondary operations. Mativenga and Rajemi [28] showed that the selection of cutting conditions based on a minimum energy footprint criterion can lead to an important decrease in the energy footprint of the machining process compared with that obtained the cutting conditions recommended by tool manufactures; Fang et al. [29] applied a model of general multi-objective mixed-integer linear programming to machining in an attempt to reduce power consumption and the carbon footprint. Finally, Yingjie [30] concluded that it is necessary to research energy efficiency techniques in machining processes through the optimization of mechanical configurations and cutting parameters, whereas that Peng and $\mathrm{Xu}$ [31] affirmed that a future comprehensive data analysis in terms of energy consumption should include materials, machine tools, cutting tools and energy. Despite these advances, it is necessary to know which cutting conditions are significant in terms of their effects on energy or $\mathrm{CO}_{2}$-eq emissions. Moreover, conditions can be easily comparable if both the energy and emissions are related to the material removed ratio (MRR).

Although many problems are related to policies, particularly those linked to the type of energy generated, it can be made decisions on industrial processes to mitigate the effects. The objectives of this paper are:(i) to evaluate the influence of the cutting conditions and insert characteristics on the energy required and the $\mathrm{CO}_{2}$-eq emissions per MRR during the dry machining of Ti6Al4V alloy, with the aim of defining parameters that contribute to reducing the influence of this process on greenhouse gas emissions, and (ii) to determine the contribution of cutting tools to $\mathrm{CO}_{2}$-eq emissions.

\section{Experimental Section}

This section describes the experimental procedure used to obtain the values of the forces that allow for the calculation of the energy, the calculation procedure to consider the energy mix and the emissions factor of materials, as well as the statistical methodology followed according to Taguchi's method.

\subsection{Experimental Procedure}

Ti6Al4V alloy bars have been used due to the importance of this material in the industry. The operation selected is turning, particularly orthogonal cutting, because cylindrical parts are components of many titanium products, such as biomedical implants, vessels, hubs, fasteners, and many other components. Some main properties of this alloy are shown in Table 1 [32].

Table 1. Proprieties of the Ti6Al4V alloy.

\begin{tabular}{cc}
\hline Density & $\mathbf{4 . 4 3} \mathbf{g} / \mathrm{cm}^{\mathbf{3}}$ \\
\hline Hardness, Brinell & 360 \\
Thermal conductivity & $6.70 \mathrm{~W} / \mathrm{mK}$ \\
Melting point & $1604-1660{ }^{\circ} \mathrm{C}$ \\
Beta transus & $980{ }^{\circ} \mathrm{C}$ \\
\hline
\end{tabular}

Several high-performance inserts have been chosen; they are recommended by the tool manufacturers for the machining of titanium, particularly SECO (Seco Group, Fagersta, Sweden), the cutting tool manufacturer selected in these tests. According ISO 1832 nomenclature [33], the inserts are as follows: CNMG 120408 MF1 890 (hereinafter CNMG), CNMG 120408 MF1 CP500 (hereinafter CNMG PVD), WNMG 060408 MF1 890 (hereinafter WNMG) and WNMG 060408 MF1 CP500 (hereinafter WNMG PVD). Thus, uncoated and coated inserts are considered. The coating is achieved by physical vapor deposition (PVD). The material coded 890 is cobalt-cemented tungsten 
carbide, WC with $6 \%$ Co as binder, manufactured by powder metallurgy technology. These coatings are more environmentally friendly than others, such as those generated by chemical vapor deposition (CVD), which requires more operations for their manufacturing [34]; this feature was taken into account when selecting the coatings investigated in this study. These tools have been selected because they provide good results in Ti6Al4V due to good machinability [35]. The tool chip breaker (MF1) used is a medium type that is adequate for finishing and roughing operations is shown in Table 2 on the images of each insert. The difference between CNMG and WNMG is the number of edges (four and six, respectively) and the cutting length of the edge (le) is 12.7 and $9.525 \mathrm{~mm}$, respectively. According to the ISO nomenclature, all of the inserts have the same cutting angle $\left(80^{\circ}\right)$, clearance angle $\left(0^{\circ}\right)$, clearance thickness $(0.13 \mathrm{~mm})$, and nose radius $(0.8 \mathrm{~mm})$. The weight of the insert type CNMG is $0.02223 \mathrm{~kg}$, and the weight of insert type WNMG is $0.01075 \mathrm{~kg}$. The coating is titanium nitride (TiN) plus titanium aluminum nitride (TiAlN) via PVD. This coating is selected because its good wear resistance, increasing the tool life [36].

Table 2. Characteristics of the inserts.

\begin{tabular}{|c|c|c|c|c|}
\hline Code & WNMG & WNMG PVD & CNMG & CNMG PVD \\
\hline $\begin{array}{l}\text { Insert with pointed } \\
\text { tool chip breaker }\end{array}$ & 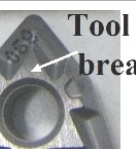 & & - & $\begin{array}{l}\text { ol chip } \\
\text { eaker }\end{array}$ \\
\hline Material & WC & WC & WC & WC \\
\hline Coating & - & $\mathrm{TiN}+\mathrm{TiAlN}$ & - & $\mathrm{TiN}+\mathrm{TiAlN}$ \\
\hline Number of edges & 6 & 6 & 4 & 4 \\
\hline $\begin{array}{l}\text { Cutting length, } \\
\text { le (mm) }\end{array}$ & 9.525 & 9.525 & 12.7 & 12.7 \\
\hline
\end{tabular}

The ranges of cutting conditions are the following: cutting depths $(d), 1,2$ and $3 \mathrm{~mm}$, feed rate $(f)$, 0.1 and $0.2 \mathrm{~mm} / \mathrm{rev}$; and cutting speed $(v c), 50,100$ and $150 \mathrm{~m} / \mathrm{min}$. Under these cutting conditions, it is possible to find regions of low, moderate and high tool wear [37]. To maintain a constant spindle speed, bars of different diameters were used: $17.2 \mathrm{~mm}$ for $v c=50 \mathrm{~m} / \mathrm{min}, 34.4 \mathrm{~mm}$ for $v c=100 \mathrm{~m} / \mathrm{min}$ and $51.6 \mathrm{~mm}$ for $v c=150 \mathrm{~m} / \mathrm{min}$. The tests were performed in dry conditions because it is more environmental friendly to avoid the use of cutting fluids [14].

The equipment used includes a Kistler-type 9257B piezoelectric dynamometer with a Kistler-type 5070A multi-channel charge amplifier (Kistler Group, Winterthur, Switzerland) installed in an EMCO CNC lathe (EMCO Maier GesmbH, Hallein, Austria). The data acquisition software to convert the electrical signal into mechanical units is DasyLab (Measurement Computing Corporation, Norton, MA, USA). The data collected directly include the cutting force $\left(\mathrm{F}_{\mathrm{c}}\right)$, back force $\left(\mathrm{F}_{\mathrm{p}}\right)$ and feed force $\left(\mathrm{F}_{\mathrm{f}}\right)$ (see Figure 1). In this manner, all of the forces are considered for a total energy calculation. The energy required for the tool change was also considered. These aspects are important because in machining, the total energy is much higher than the cutting energy [38]. With this information, it is possible to calculate the cutting, feed, active and drive power. From these values, the ratio of energy to MRR can be finally calculated. The machine efficiency is assumed to be $90 \%$, which is within the typical machine efficiency range of $80 \%$ to $90 \%$ [17]. This efficiency contributes to the absolute value of the energy, but considering the same technology level of the machines, it does not contribute to a different result about insert tools behavior.

The tool life was analyzed by a three-dimensional measurement device with a TESA VISIO laser sensor (TESA SA, Renens, Switzerland), which can determine the wear of each cutting edge at each tool insert. Although, the energy consumption can increase due to tool wear, because the forces required are higher [39], in these experiments, each insert is used for its lifespan. 


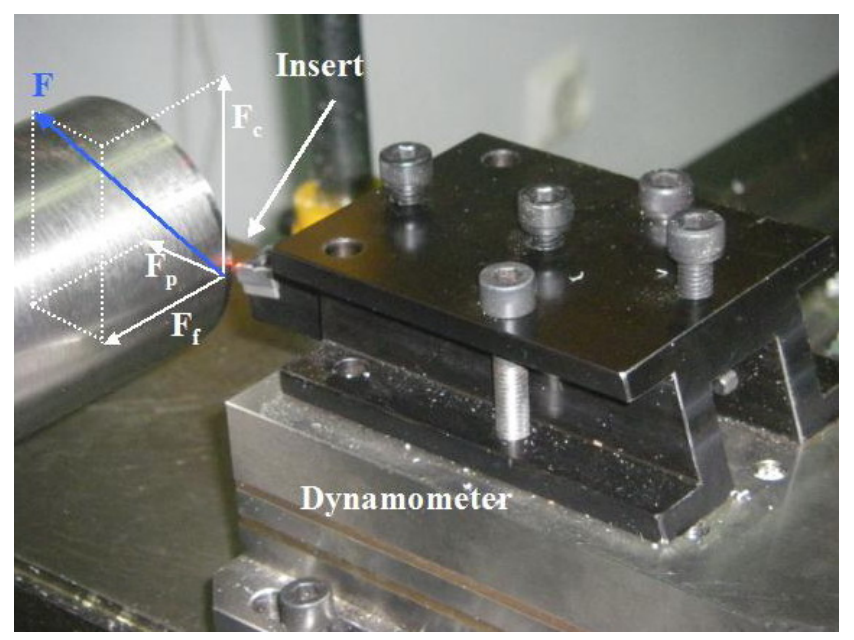

Figure 1. Assembly of the dynamometer, insert and part, and types of forces.

\subsection{Calculation Procedure}

This calculation considers the emissions derived from the energy consumed during the machining and the manufacturing of the inserts. The emissions resulting from the titanium manufacturing are not considered because they are common in all cases; thus, they do not contribute to identifying the ideal conditions. $\mathrm{CO}_{2}$-eq emissions are calculated considering the Spanish energy mix. Table 3 describes the Spanish energy mix; as shown in the table, the emission factor is 0.44 tonnes $\mathrm{CO}_{2}$-eq/GJ [40]. In this country, there is a high percentage of clean energy, so the results could be considerably higher in other countries. Moreover, the emissions derived from the inserts, particularly from WC manufactured by a sintering process, have a coefficient of 1.34 tonnes of $\mathrm{CO}_{2}$-eq per tonne of manufactured product [41], in addition to the manufacturing process of the insert coatings, which are formed by physical vapor deposition, which adds 0.08 tonnes of $\mathrm{CO}_{2}$-eq per tonne of manufactured product [41]. Because these coefficients are lifecycle emission contributions, all of these coefficients and the weight of the inserts were taken into account in the calculation of $\mathrm{CO}_{2}$-eq emissions, which were performed using SimaPro software (Pré Consultants, Amersfoort, The Netherlands) [42], to obtain the results presented in Section 3.

Table 3. Origin of electrical energy.

\begin{tabular}{cc}
\hline Origin & Percentage (\%) \\
\hline Coal & 11.3 \\
Combined cycle & 9.1 \\
Wind & 25.0 \\
Hydro & 16.2 \\
Nuclear & 20.5 \\
Photovoltaic solar & 2.4 \\
Renewable thermal & 2.1 \\
Thermal solar & 0.8 \\
Cogeneration and remaining & 12.6 \\
\hline
\end{tabular}

In these calculations, it is necessary to consider the number of inserts required for machining Ti6Al4V alloy. In this sense, the tool life is an important variable. ISO 3685 [43] establishes the limit on flank tool wear (VB) at $0.3 \mathrm{~mm}$, which has been considered in the calculation of the number of tools required during the process and will affect the emissions outcomes due to the production of tools. Once an insert achieves a wear of $0.3 \mathrm{~mm}$, a new insert replaces it. Preliminary tests were executed to determine the tool life, measuring the growth of flank wear, and the machining time for 
each edge and each cutting condition. Once the edge life is known, the tool was changed during the tests at the appropriate time, and the $\mathrm{CO}_{2}$-eq emissions generated from the energy consumed during the times of change were taken into account. The overall operation time was the sum of insert lifespan plus an average of $90 \mathrm{~s}$ of change time per insert. In order to establish proper tool life comparisons, the total number of inserts required to machining a cubic meter of raw material was considered. For energy calculation only machining and change times were considered, but for $\mathrm{CO}_{2}$-eq calculation tool manufacturing impact was added. This approach allows the tool comparison and also it determines whether the energy required for the process is sufficient for insert selection. Both the energy requirements and the emissions that are common to any type of tool they have not been taken into account, so a differential comparison and selection procedure is provided.

\subsection{Statistical Procedure}

A design of experiments by the Taguchi methodology has been performed [44]. To reduce the number of tests, the orthogonal array L36 $\left(2^{3} \times 3^{13}\right)$ has been chosen because it combines a maximum of three factors with two levels and thirteen factors with three levels. The factors and levels are shown in Table 4, in which the coating, le and $f$ have two levels and $v c$ and $d$ have three levels.

Table 4. Factors and levels of the design of experiments.

\begin{tabular}{ccccccc}
\hline Level & Factor & Coating & $\begin{array}{c}\text { Tool Cutting } \\
\text { Length, } \boldsymbol{l} \boldsymbol{( \mathbf { m m } )}\end{array}$ & $\begin{array}{c}\text { Feed Rate, } f \\
(\mathbf{m m} / \mathbf{r e v})\end{array}$ & $\begin{array}{c}\text { Cutting Speed, } \\
v c(\mathbf{m} / \mathbf{m i n})\end{array}$ & $\begin{array}{c}\text { Cutting Depth, } \\
\boldsymbol{d}(\mathbf{m m})\end{array}$ \\
\hline 1 & Uncoated & 9.525 & 0.1 & 50 & 1 \\
2 & PVD & 12.7 & 0.2 & 100 & 2 \\
3 & - & - & - & 150 & 3 \\
\hline
\end{tabular}

The measurement is given via the signal-to-noise ratio $(\mathrm{S} / \mathrm{N})$, which represents the relationship between the signal or mean and the noise or variance [44]. Taguchi considered several models of $\mathrm{S} / \mathrm{N}$ : "smallest is better", "nominal is better" and "larger is better"; in this study, "smaller is better" is analyzed because the variables are energy and $\mathrm{CO}_{2}$-eq emissions. This methodology has been used in the analysis of manufacturing processes $[45,46]$ because it can be used to optimize the parameters that have a major influence on the variables considered. Equation (1) represents the relationship "smaller is better", where $n$ is the number of tests and $y_{i}$ is the measurement in the $i$ th trial of the objective variable. In this investigation, $y_{i}$ is the energy and the $\mathrm{CO}_{2}$-eq emissions by MRR. MRR is the product of the cutting conditions: $f, v c$ and $d$. For the $\mathrm{S} / \mathrm{N}$ ratio, "smaller is better" is interpreted as higher values being preferred [44].

$$
S / N=-\log \left(\frac{1}{n} \sum_{i=1}^{n} y_{i}^{2}\right)
$$

An analysis of variance (ANOVA) has been performed to find the significant factors and interactions in the $\mathrm{S} / \mathrm{N}$ ratio under a confidence interval of $95 \%$. Therefore, the factor or the interaction is significant if the P-value is less than 0.05 [47]. Moreover, a regression analysis is conducted to verify the relationship between the factors and variables and between energy and emissions. The Statgraphics software (Statpoint Technologies, Inc., Warrenton, VA, USA) was used for the statistical analyses [48].

\section{Results and Discussion}

The factors and levels presented in Table 4 are displayed in greater detail in Table 5 to allow a clear identification of the values associated with each factor at each level. The following results show the value of the total energy per MRR, including the energy achieved by the cutting, back and feed forces. 
Table 5. Values of the factors at each level.

\begin{tabular}{|c|c|c|c|c|c|c|c|c|c|c|}
\hline \multirow{2}{*}{$\begin{array}{l}\text { No. } \\
\text { Test }\end{array}$} & \multicolumn{5}{|c|}{ Factors and Levels } & \multicolumn{5}{|c|}{ Values of Factors at Each Level } \\
\hline & Coating & $\begin{array}{c}\text { Tool } \\
\text { Cutting } \\
\text { Length, le }\end{array}$ & $\begin{array}{c}\text { Feed } \\
\text { Rate, } f\end{array}$ & $\begin{array}{l}\text { Cutting } \\
\text { Speed, } v c\end{array}$ & $\begin{array}{l}\text { Cutting } \\
\text { Depth, } d\end{array}$ & Coating & $\begin{array}{l}\text { Tool Cutting } \\
\text { Length, } l e \\
\text { (mm) }\end{array}$ & $\begin{array}{l}\text { Feed Rate, } \\
f(\mathrm{~mm} / \mathrm{rev})\end{array}$ & $\begin{array}{l}\text { Cutting } \\
\text { Speed, } v c \\
(\mathrm{~m} / \mathrm{min})\end{array}$ & $\begin{array}{l}\text { Cutting } \\
\text { Depth, } d \\
\text { (mm) }\end{array}$ \\
\hline 1 & 1 & 1 & 1 & 1 & 1 & Uncoated & 9.525 & 0.1 & 50 & 1 \\
\hline 2 & 1 & 1 & 1 & 1 & 2 & Uncoated & 9.525 & 0.1 & 50 & 2 \\
\hline 3 & 1 & 1 & 1 & 1 & 3 & Uncoated & 9.525 & 0.1 & 50 & 3 \\
\hline 4 & 1 & 2 & 2 & 1 & 1 & Uncoated & 12.7 & 0.2 & 50 & 1 \\
\hline 5 & 1 & 2 & 2 & 1 & 2 & Uncoated & 12.7 & 0.2 & 50 & 2 \\
\hline 6 & 1 & 2 & 2 & 1 & 3 & Uncoated & 12.7 & 0.2 & 50 & 3 \\
\hline 7 & 2 & 1 & 2 & 1 & 1 & PVD & 9.525 & 0.2 & 50 & 1 \\
\hline 8 & 2 & 1 & 2 & 1 & 2 & PVD & 9.525 & 0.2 & 50 & 2 \\
\hline 9 & 2 & 1 & 2 & 1 & 3 & PVD & 9.525 & 0.2 & 50 & 3 \\
\hline 10 & 2 & 2 & 1 & 1 & 1 & PVD & 12.7 & 0.1 & 50 & 1 \\
\hline 11 & 2 & 2 & 1 & 1 & 2 & PVD & 12.7 & 0.1 & 50 & 2 \\
\hline 12 & 2 & 2 & 1 & 1 & 3 & PVD & 12.7 & 0.1 & 50 & 3 \\
\hline 13 & 1 & 1 & 1 & 2 & 1 & Uncoated & 9.525 & 0.1 & 100 & 1 \\
\hline 14 & 1 & 1 & 1 & 2 & 2 & Uncoated & 9.525 & 0.1 & 100 & 2 \\
\hline 15 & 1 & 1 & 1 & 2 & 3 & Uncoated & 9.525 & 0.1 & 100 & 3 \\
\hline 16 & 1 & 2 & 2 & 2 & 1 & Uncoated & 12.7 & 0.2 & 100 & 1 \\
\hline 17 & 1 & 2 & 2 & 2 & 2 & Uncoated & 12.7 & 0.2 & 100 & 2 \\
\hline 18 & 1 & 2 & 2 & 2 & 3 & Uncoated & 12.7 & 0.2 & 100 & 3 \\
\hline 19 & 2 & 1 & 2 & 2 & 1 & PVD & 9.525 & 0.2 & 100 & 1 \\
\hline 20 & 2 & 1 & 2 & 2 & 2 & PVD & 9.525 & 0.2 & 100 & 2 \\
\hline 21 & 2 & 1 & 2 & 2 & 3 & PVD & 9.525 & 0.2 & 100 & 3 \\
\hline 22 & 2 & 2 & 1 & 2 & 1 & PVD & 12.7 & 0.1 & 100 & 1 \\
\hline 23 & 2 & 2 & 1 & 2 & 2 & PVD & 12.7 & 0.1 & 100 & 2 \\
\hline 24 & 2 & 2 & 1 & 2 & 3 & PVD & 12.7 & 0.1 & 100 & 3 \\
\hline 25 & 1 & 1 & 1 & 3 & 1 & Uncoated & 9.525 & 0.1 & 150 & 1 \\
\hline 26 & 1 & 1 & 1 & 3 & 2 & Uncoated & 9.525 & 0.1 & 150 & 2 \\
\hline 27 & 1 & 1 & 1 & 3 & 3 & Uncoated & 9.525 & 0.1 & 150 & 3 \\
\hline 28 & 1 & 2 & 2 & 3 & 1 & Uncoated & 12.7 & 0.2 & 150 & 1 \\
\hline 29 & 1 & 2 & 2 & 3 & 2 & Uncoated & 12.7 & 0.2 & 150 & 2 \\
\hline 30 & 1 & 2 & 2 & 3 & 3 & Uncoated & 12.7 & 0.2 & 150 & 3 \\
\hline 31 & 2 & 1 & 2 & 3 & 1 & PVD & 9.525 & 0.2 & 150 & 1 \\
\hline 32 & 2 & 1 & 2 & 3 & 2 & PVD & 9.525 & 0.2 & 150 & 2 \\
\hline 33 & 2 & 1 & 2 & 3 & 3 & PVD & 9.525 & 0.2 & 150 & 3 \\
\hline 34 & 2 & 2 & 1 & 3 & 1 & PVD & 12.7 & 0.1 & 150 & 1 \\
\hline 35 & 2 & 2 & 1 & 3 & 2 & PVD & 12.7 & 0.1 & 150 & 2 \\
\hline 36 & 2 & 2 & 1 & 3 & 3 & PVD & 12.7 & 0.1 & 150 & 3 \\
\hline
\end{tabular}

They are high (see Table 6) compared with those obtained with other materials such as aluminum alloys [49], but are calculated per cubic meter, and the density of Ti6Al4V is higher (see Table 1) that that of aluminum based alloys. Therefore, the required high forces result in high energy consumption and $\mathrm{CO}_{2}$-eq emissions. The $\mathrm{S} / \mathrm{N}$ ratios are shown in Table 6 . The results show that completely different outcomes are obtained with different cutting conditions. In a first approach, better results for energy and emissions (see line 6 of Table 6) are obtained with an uncoated insert, high cutting length, and the cutting conditions $f=0.2 \mathrm{~mm} / \mathrm{rev}, v c=50 \mathrm{~m} / \mathrm{min}$ and $d=3 \mathrm{~mm}$. The worst results are achieved with a coated insert, low cutting length, and cutting conditions $f=0.2 \mathrm{~mm} / \mathrm{rev}$, $v c=150 \mathrm{~m} / \mathrm{min}$ and $d=2 \mathrm{~mm}$ (see line 32 of Table 6 ).

Table 6. Calculated energy/MRR, $\mathrm{CO}_{2}$-eq emissions and edge life.

\begin{tabular}{cccccc}
\hline No. Test & $\begin{array}{c}\text { Energy/MRR } \\
\left(\mathbf{G J} / \mathbf{m}^{\mathbf{3}}\right)^{*}\end{array}$ & $\begin{array}{c}\mathbf{S} / \mathbf{N} \\
(\text { Energy/MRR) }\end{array}$ & $\begin{array}{c}\mathbf{C O}_{\mathbf{2}} \text {-eq } \\
\text { Emissions/MRR } \\
\mathbf{( k g C O}_{\mathbf{2}} \mathbf{m}^{\mathbf{3}} \mathbf{~}^{*}\end{array}$ & $\begin{array}{c}\text { S/N (CO } \mathbf{2} \text {-eq } \\
\text { Emissions/MRR) }\end{array}$ & Edge Life (min) \\
\hline 1 & 1.90 & -5.593 & 869.32 & -58.785 & 14.41 \\
2 & 1.84 & -5.315 & 831.75 & -58.400 & 10.84 \\
3 & 1.51 & -3.595 & 683.23 & -56.691 & 8.50 \\
4 & 1.74 & -4.796 & 803.02 & -58.094 & 19.90 \\
5 & 0.98 & 0.127 & 454.89 & -53.158 & 15.72 \\
6 & 0.71 & 2.912 & 331.79 & -50.419 & 12.80 \\
7 & 2.35 & -7.421 & 1042.54 & -60.362 & 29.80 \\
8 & 1.62 & -4.179 & 718.17 & -57.125 & 23.70 \\
\hline
\end{tabular}


Table 6. Cont.

\begin{tabular}{|c|c|c|c|c|c|}
\hline No. Test & $\begin{array}{c}\text { Energy/MRR } \\
\left(\mathrm{GJ} / \mathrm{m}^{3}\right)^{*}\end{array}$ & $\begin{array}{c}\text { S/N } \\
\text { (Energy/MRR) }\end{array}$ & $\begin{array}{c}\mathrm{CO}_{2}-\mathrm{eq} \\
\text { Emissions/MRR } \\
\left(\mathrm{kgCO}_{2} / \mathrm{m}^{3}\right)^{*}\end{array}$ & $\begin{array}{c}\mathrm{S} / \mathrm{N}\left(\mathrm{CO}_{2}-\mathrm{eq}\right. \\
\text { Emissions/MRR) }\end{array}$ & Edge Life (min) \\
\hline 9 & 1.94 & -5.774 & 857.88 & -58.669 & 19.80 \\
\hline 10 & 1.65 & -4.330 & 784.39 & -57.891 & 27.03 \\
\hline 11 & 1.60 & -4.100 & 743.01 & -57.420 & 20.23 \\
\hline 12 & 1.41 & -2.963 & 650.93 & -56.271 & 17.23 \\
\hline 13 & 1.97 & -5.891 & 908.12 & -59.163 & 5.81 \\
\hline 14 & 1.65 & -4.372 & 757.76 & -57.591 & 3.78 \\
\hline 15 & 1.73 & -4.746 & 799.31 & -58.054 & 2.10 \\
\hline 16 & 1.96 & -5.864 & 940.30 & -59.465 & 4.78 \\
\hline 17 & 1.50 & -3.551 & 726.49 & -57.225 & 2.80 \\
\hline 18 & 1.16 & -1.303 & 579.35 & -55.259 & 1.80 \\
\hline 19 & 1.24 & -1.899 & 565.86 & -55.054 & 6.28 \\
\hline 20 & 1.74 & -4.800 & 781.83 & -57.862 & 3.92 \\
\hline 21 & 1.42 & -3.069 & 642.11 & -56.152 & 2.45 \\
\hline 22 & 1.50 & -3.515 & 728.62 & -57.250 & 11.50 \\
\hline 23 & 1.53 & -3.714 & 727.25 & -57.234 & 7.30 \\
\hline 24 & 1.82 & -5.187 & 864.03 & -58.731 & 4.16 \\
\hline 25 & 2.06 & -6.291 & 1001.11 & -60.010 & 1.69 \\
\hline 26 & 1.45 & -3.212 & 681.03 & -56.663 & 1.86 \\
\hline 27 & 1.71 & -4.685 & 816.68 & -58.241 & 0.83 \\
\hline 28 & 1.67 & -4.434 & 863.42 & -58.724 & 1.93 \\
\hline 29 & 1.48 & -3.416 & 737.39 & -57.354 & 1.44 \\
\hline 30 & 1.10 & -0.797 & 587.43 & -55.379 & 0.80 \\
\hline 31 & 1.92 & -5.680 & 883.00 & -58.919 & 2.22 \\
\hline 32 & 2.33 & -7.342 & 1050.74 & -60.430 & 1.66 \\
\hline 33 & 1.54 & -3.727 & 703.30 & -56.943 & 1.10 \\
\hline 34 & 1.34 & -2.563 & 690.78 & -56.787 & 5.20 \\
\hline 35 & 1.40 & -2.915 & 687.68 & -56.748 & 3.67 \\
\hline 36 & 1.41 & -3.014 & 743.04 & -57.420 & 1.43 \\
\hline
\end{tabular}

*These values represent the means of three trials in each test.

As observed in the same table, the edge life is $12.85 \mathrm{~min}$ in the best situation (CNMG tool) and 1.72 in the worst case (WNMG PVD tool). Because the edge life varies from $29.8 \mathrm{~min}$ (WNMG PVD tool) to $0.8 \mathrm{~min}$ (CNMG tool), the influence of tools is not clear. In addition to these conditions, it is important to determine the significant factors, which can provide information about the general behavior.

\subsection{Energy/MRR}

The results of the $\mathrm{S} / \mathrm{N}$ ratio related to energy/MRR have been subjected to a multifactor ANOVA considering the main factors and their interactions. The outcomes are shown in Table 7. The ANOVA table shows the sum of squares, degrees of freedom, mean square, F-ratio according to a Fisher-Snedecor test and P-value of the main factors (coating, le, $f, v c$ and $d$ ) and the interactions (coating- $d$, and $l e-v c$ ). Only the significant interactions are given in this table; therefore, the interactions coating- $v c$, coating- $f$, coating-le, $l e-f, l e-d, f-d, f-v c$ and $v c-d$ are not significant. The ANOVA shows two significant factors, $l e$ and $d$, as their P-values are less than 0.05 (see Table 7). 
Table 7. ANOVA for the $\mathrm{S} / \mathrm{N}$ ratio (Energy/MRR).

\begin{tabular}{cccccc}
\hline Source & Sum of Squares & Degrees of Freedom & Mean Square & F-Ratio & $p$-value \\
\hline Coating & 3.589 & 1 & 3.589 & 2.40 & 0.1470 \\
$L e$ & 32.431 & 1 & 32.431 & 21.72 & 0.0006 \\
$f$ & 3.353 & 1 & 3.353 & 2.25 & 0.1598 \\
$V c$ & 0.490 & 2 & 0.245 & 0.16 & 0.8505 \\
$d$ & 20.780 & 2 & 10.390 & 6.96 & 0.0099 \\
coating- $d$ & 16.560 & 2 & 8.280 & 5.55 & 0.0197 \\
le-vc & 12.886 & 2 & 6.443 & 4.32 & 0.0387 \\
Residual & 17.917 & 12 & 1.493 & & \\
Total (corrected) & 143.98 & 35 & & & \\
\hline
\end{tabular}

The percentage of influence is $22.52 \%$ le and $14.43 \% d$, obtained by the ratio between the sum of squares of a factor and the total (Table 7). The result for $l e$ is interesting because it can influence tool design. Figure 2 shows that an increase in $l e$ is recommended. Thus, an increase in le results in an increase in the $\mathrm{S} / \mathrm{N}$ ratio (Energy/MRR). A possible cause is that the shape of the insert makes chip evacuation difficult and can therefore influence deformed chips and removed chips. Thus, from the energy perspective, CNMG inserts have better results than WNMG inserts. The outcomes of $d$ are also of interest because an increase in $d$ results in a higher $\mathrm{S} / \mathrm{N}$ ratio. This finding is consistent with the effect of $d$ on the life of the tool, as noted in Table 6; increasing $d$ also increases the tool life. A greater $d, 3 \mathrm{~mm}$ in the range used, results in more material removed per unit of time; therefore, the high performance is more sustainable.

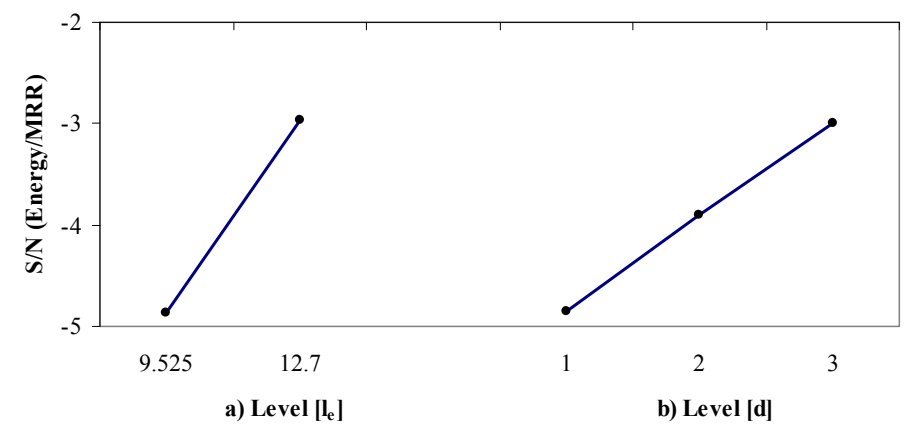

Figure 2. Values of the $\mathrm{S} / \mathrm{N}$ ratios of significant main factors for energy/MRR.

With respect to significant interactions (see Table 7), only coating- $d$ appears and has a positive effect compared to the uncoated insert and a $d$ of $3 \mathrm{~mm}$ (see Figure 3). This finding is consistent with the results shown in Figure 3; the coating does not positively influence the energy because of the increase in friction.

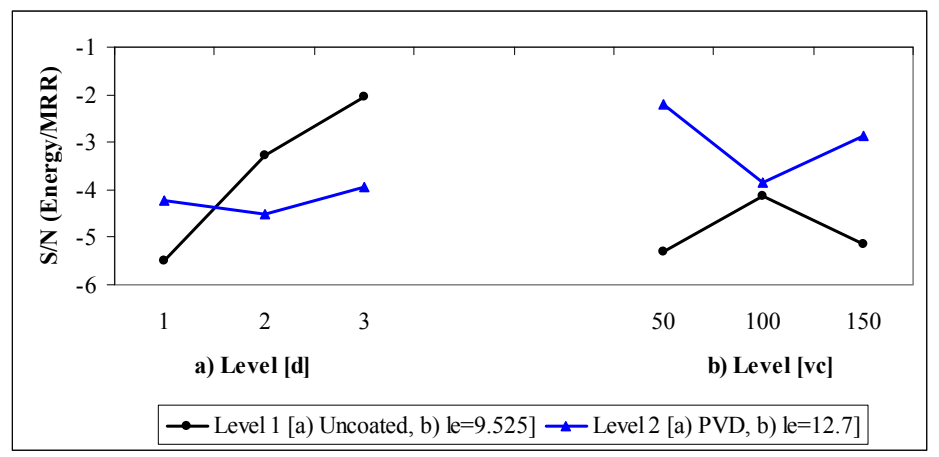

Figure 3. Values of the $\mathrm{S} / \mathrm{N}$ ratio of the significant interactions for energy/MRR. 
The results for the interaction $l e-v c$ are different from the results for le. An increase in $l e$ is recommended over a lower $v c$. The outcomes are consistent with the results in Figure 2. Additionally, a lower $v c(50 \mathrm{~mm} / \mathrm{min})$ results in a lower energy consumption.

\section{2. $\mathrm{CO}_{2}$-eq Emissions/MRR}

Table 8 shows the ANOVA; the factors $l e$ and $d$ are statistically significant, as in the S/N ratio (energy/MRR) and with the same effect (see Figure 4). The significant interactions are coating- $d$ and $l e-v c$, as for the $\mathrm{S} / \mathrm{N}$ ratio (energy/MRR), but in this case, coating- $v c$ also has a P-value less than 0.05 . In this case, the percentage of influence is $16.03 \% d$ and $12.55 \%$ le. The influence of $l e$ is considerably lower than in the study of energy, possibly due to the influence of the coating-vc interaction, which is absent in the significant interactions of the $\mathrm{S} / \mathrm{N}$ ratio (energy/MRR). Thus, although there is a strong relationship between energy and $\mathrm{CO}_{2}$-eq emissions, in the last case, the influence of tool life can be considered. In fact, the emissions are increased with the number of tools manufactured. The effect of significant interactions is shown in Figure 5.

Table 8. ANOVA of the $\mathrm{S} / \mathrm{N}$ ratio $\left(\mathrm{CO}_{2}\right.$-eq emissions/MRR).

\begin{tabular}{cccccc}
\hline Source & Sum of Squares & Degrees of Freedom & Mean Square & F-Ratio & $p$-value \\
\hline Coating & 2.049 & 1 & 2.049 & 1.38 & 0.2624 \\
$l e$ & 16.382 & 1 & 16.382 & 11.05 & 0.0061 \\
$f$ & 4.519 & 1 & 4.519 & 3.05 & 0.10635 \\
$v c$ & 4.468 & 2 & 2.234 & 1.51 & 0.2606 \\
$d$ & 20.934 & 2 & 10.467 & 7.06 & 0.0094 \\
coating- $v c$ & 12.062 & 2 & 6.031 & 4.07 & 0.0448 \\
coating- $d$ & 15.270 & 2 & 7.635 & 5.15 & 0.0243 \\
le-vc & 13.662 & 2 & 6.831 & 4.61 & 0.0327 \\
Residual & 17.784 & 12 & 1.482 & & \\
Total (corrected) & 130.553 & 35 & & & \\
\hline
\end{tabular}

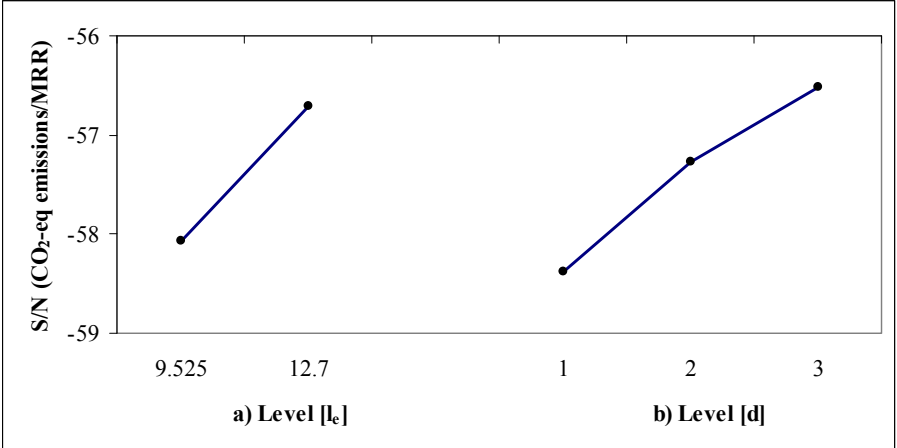

Figure 4. Values of the $\mathrm{S} / \mathrm{N}$ ratios of the significant main factors for $\mathrm{CO}_{2}$-eq emissions/MRR.

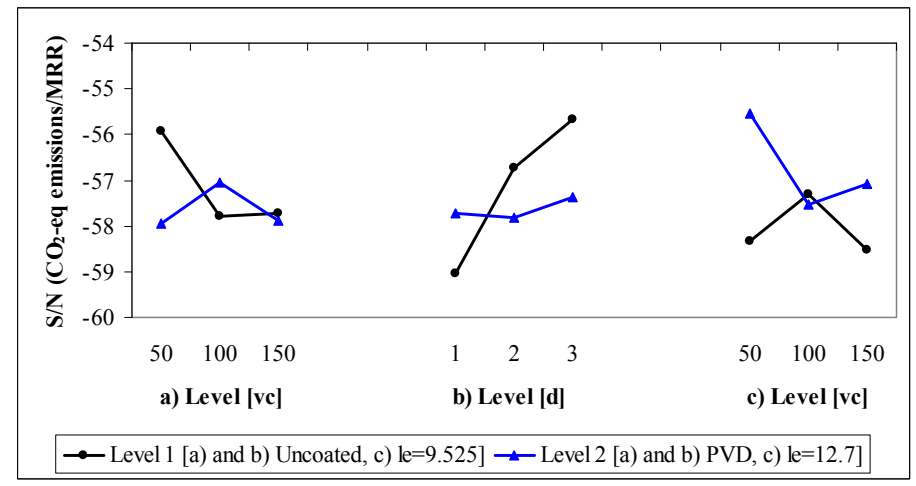

Figure 5. Values of the $\mathrm{S} / \mathrm{N}$ ratios of the significant interactions for $\mathrm{CO}_{2}$-eq emissions/MRR. 


\subsection{Contribution of Cutting Inserts to $\mathrm{CO}_{2}$-eq Emissions}

In roughing operations, which are common in machining, coatings do not have a positive influence on energy. Of the inserts evaluated, the most interesting with respect to energy/MRR was CNMG. These last considerations involve sustainability and performance objectives, which balance is important in the industry. Therefore, a longer cutting length has a positive effect. Moreover, this insert has fewer edges than WNMG.

The emissions results for the optimal energy consumption for each insert and the percentages attributed to tools are shown in Figure 6. In this figure, the number of tests is equivalent to the number of tests presented in Tables 5 and 6 to allow identification of the tool characteristics and cutting parameters. The results show that energy is a more important factor in $\mathrm{CO}_{2}$-eq emissions, as demonstrated by the finding that higher emissions result from higher energy and not from the emissions associated with tools. The ranking of the inserts from those that generate less emissions to those that generate higher emission is the following: CNMG, CNMG PVD, WNMG PVD and WNMG. These results are consistent with those obtained for energy consumption. As expected, the coating contribution is sufficiently small, and as a result, the percentage is conditioned by the total emissions and not by the coating.

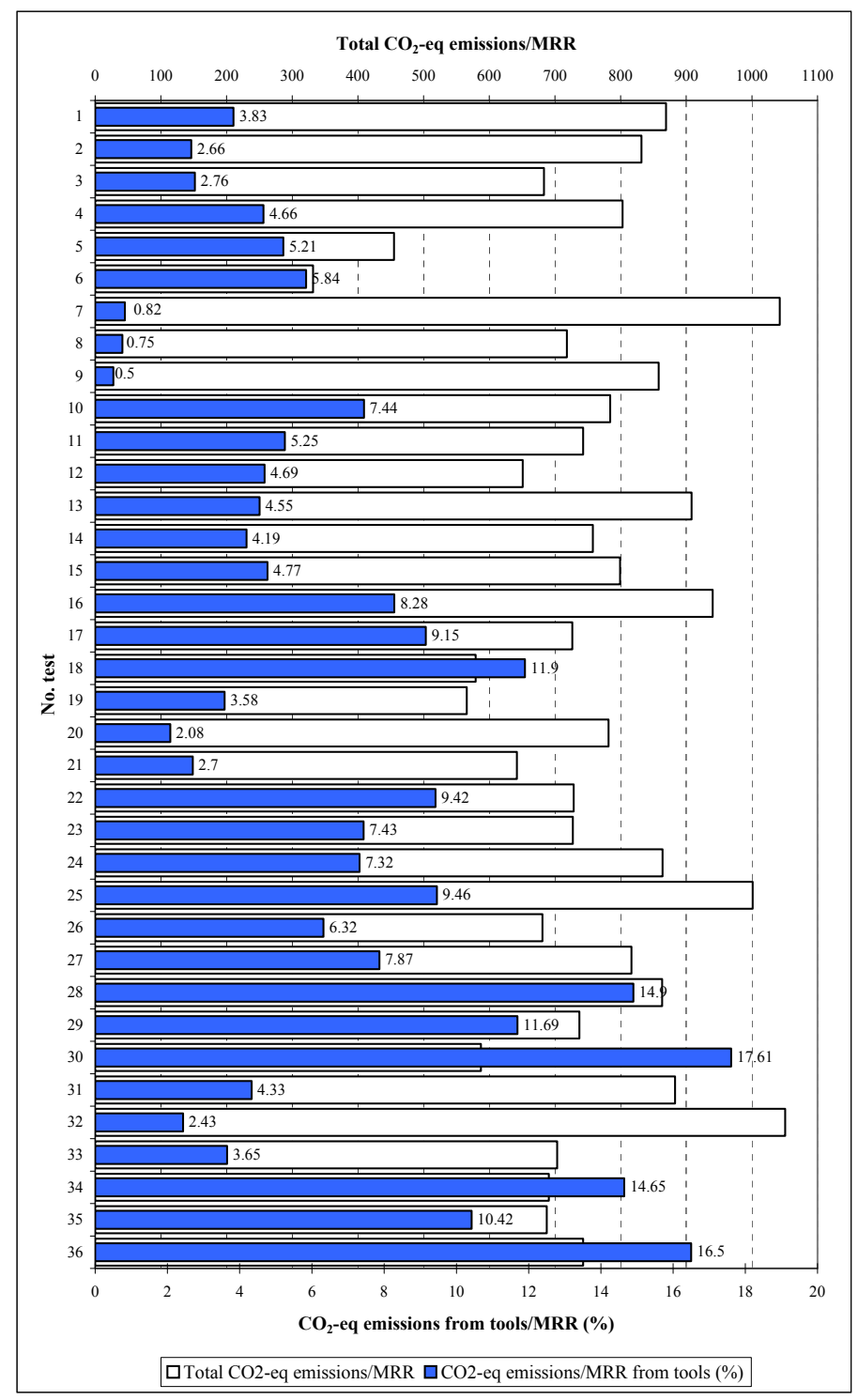

Figure 6. Contribution of tools to $\mathrm{CO}_{2}$-eq emissions/MRR as a percentage. 
As shown in Figure 6, the percentages are between $17.61 \%$ and $0.5 \%$. The uncoated insert type CNMG, with $f=0.2 \mathrm{~mm} / \mathrm{rev}, v c=150 \mathrm{~m} / \mathrm{min}$ and $d=3 \mathrm{~mm}$, has the greatest contribution (see line 30 of Table 6), followed by coated insert type CNMG, with $f=0.1 \mathrm{~mm} / \mathrm{rev}, v c=150 \mathrm{~m} / \mathrm{min}$ and $d=3 \mathrm{~mm}$ (line 36 of Table 6) and the uncoated insert type CNMG, with $f=0.2 \mathrm{~mm} / \mathrm{rev}, v c=150 \mathrm{~m} / \mathrm{min}$ and $d=50 \mathrm{~mm}$ (line 28 of Table 6). The lowest contributions of the tools are found for coated insert type WNMG, with $f=0.2, v c=50 \mathrm{~m} / \mathrm{min}$ and $d=1,2$, and $3 \mathrm{~mm}$ (lines 7, 8 and 9 of Table 6). The lower contribution obtained for the WNMG insert is a consequence of the material, even when these inserts consume more energy in machining tests.

\subsection{Evolution of Factors}

Figure 7 shows the variation of the $\mathrm{S} / \mathrm{N}$ ratios as $d$ and le are increased, and Figure 8 shows the same variation as coating and le are modified under optimal conditions. Both ratios appear to show a similar evolution.

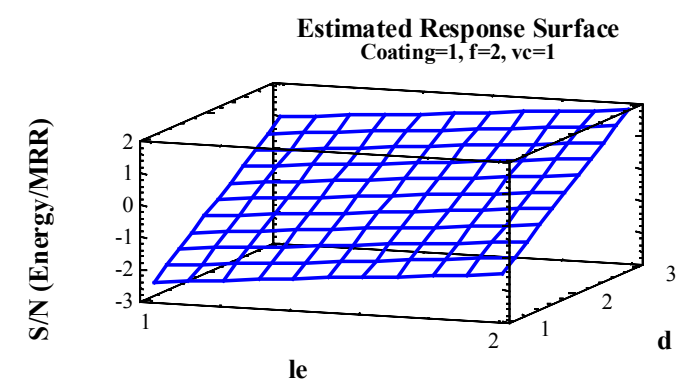

(a)

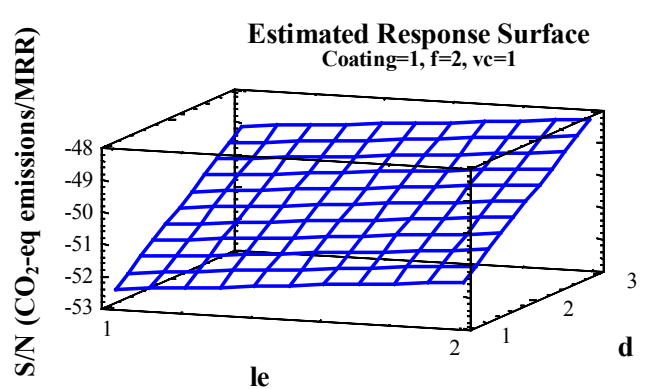

(b)

Figure 7. (a) Values of the $\mathrm{S} / \mathrm{N}$ ratio (Energy/MRR) with respect to le and $d$; (b) Values of the $\mathrm{S} / \mathrm{N}$ ratio $\left(\mathrm{CO}_{2}\right.$-eq emissions $\left./ \mathrm{MRR}\right)$ with respect to le and $d$.

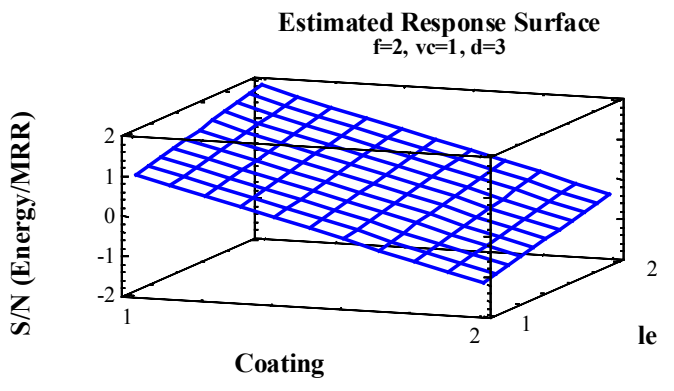

(a)

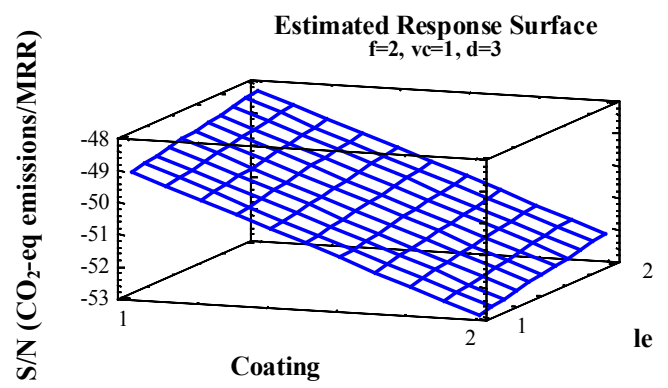

(b)

Figure 8. (a) Values of the $\mathrm{S} / \mathrm{N}$ ratio (Energy/MRR) with respect to coating and le; (b) Values of the $\mathrm{S} / \mathrm{N}$ ratio $\left(\mathrm{CO}_{2}\right.$-eq emissions/MRR) with respect to coating and le.

Therefore, linear regression can explain the relationship between S/N Energy/MRR) and S/N ( $\mathrm{CO}_{2}$-eq emissions/MRR). The output shows the results of fitting a linear model via Equation (2). The correlation is 0.9781 , and $R^{2}$ is $95.66 \%$. Figure 9 shows the model of the fitted linear regression. The calculation of the energy can be used to determine $\mathrm{CO}_{2}$-eq emissions without considering the contribution of tools:

$$
S / N\left(\mathrm{CO}_{2}-\text { eqemissions } / M R R\right)=-53.74+0.93 \times[S / N(\text { Energy } / M R R)]
$$




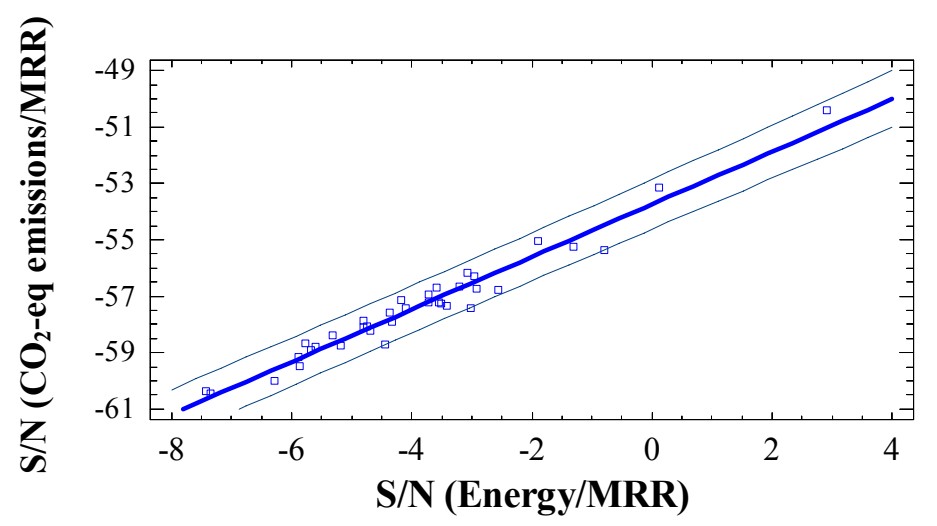

Figure 9. Fitted linear regression model.

\section{Conclusions}

We have presented a study centered on the selection of cutting inserts for environmentally efficient machining. This paper contributes to the understanding of this field by providing a quantitative evaluation of the main different technological and operational factors associated with modern machining using cutting inserts. Utilizing a widely used titanium alloy, the approach includes proper qualitative ratios of energy use and $\mathrm{CO}_{2}$ impact related to a main manufacturing activity metric (MRR). Comprehensive experimentation and a subsequent statistical analysis using the Taguchi and ANOVA techniques represent a systematic methodology for qualitative and quantitative assessment.

The methodology proposed can contribute to the conservation of resources through the identification of practices in manufacturing processes, particularly in the turning operations of Ti6Al4V alloy, that result in lower energy/MRR consumption and lower $\mathrm{CO}_{2}$-eq emissions/MRR. For both metrics, energy and emissions, the study outcomes show that a high tool cutting length and a high cutting depth were identified as significant factors. Thus, this alloy is sensitive to cutting conditions and also to tool geometry, rather than tool material.

The inserts were ranked from those that have minor effects on the energy/MRR and $\mathrm{CO}_{2}$-eq emissions/MRR to those that have major effects in these ratios: CNMG, CNMG PVD, WNMG PVD and WNMG. The coating has a low impact and an uncoated insert is a first choice for a high cutting depth and a high tool cutting length. This is a remarkable conclusion, because the use of coated inserts can be avoided in roughing operations, improving cost and performance.

This study demonstrates the need to consider cutting inserts as an element capable of reducing the machining contribution to climate change through the industrial activity. The carbon footprint is directly proportional to energy consumption. In this sense, forthcoming studies related to the sustainability and environmental impact of machining processes could focus more on the fundamental analysis of energy rather than the analysis of the downstream effect of emissions.

Acknowledgments: The authors thank the "Research Group Industrial Production and Manufacturing Engineering (IPME)", the Spanish Ministry of Economy and Competitiveness through the DPI2011-27135 and DPI2014-58007-R projects and the Industrial Engineering School-UNED through the REF2014-ICF07 project for their support.

Author Contributions: All authors contributed equally to this work. All authors have read and approved of the final manuscript.

Conflicts of Interest: The authors declare no conflicts of interest.

\section{References}

1. Intergovernmental Panel on Climate Change (IPCC). Climate Change 2014, Report; IPCC: Geneva, Switzerland, 2014. 
2. Rosen, M.A. Engineering and sustainability: Attitudes and actions. Sustainability 2013, 5, 372-386. [CrossRef]

3. Tanaka, K. Review of policies and measures for energy efficiency in industry sector. Energy Policy 2011, 39, 6532-6550. [CrossRef]

4. Zhai, Q.; Cao, H.; Zhao, X.; Yuan, C. Cost benefit analysis of using clean energy supplies to reduce greenhouse gas emissions of global automotive manufacturing. Energies 2011, 4, 1478-1494. [CrossRef]

5. Tan, X.C.; Wang, Y.Y.; Gu, B.H.; Mu, Z.K.; Yang, C. Improved methods for production manufacturing processes in environmentally benign manufacturing. Energies 2011, 4, 1391-1409. [CrossRef]

6. Domingo, R.; García, M.; Sánchez, A.; Gómez, R. A sustainable evaluation of drilling parameters for PEEK-GF30. Materials 2013, 6, 5907-5922. [CrossRef]

7. Beggs, P.J. Adaptation to impacts of climate change on aeroallergens and allergic respiratory diseases. Int. J. Environ. Res. Public Health 2010, 7, 3006-3021. [CrossRef] [PubMed]

8. Carlin, A. A Multidisciplinary, science-based approach to the economics of climate change. Int. J. Environ. Res. Public Health 2011, 8, 985-1031. [CrossRef] [PubMed]

9. Aguado, S.; Alvarez, R.; Domingo, R. Model of efficient and sustainable improvements in a lean production system through processes of environmental innovation. J. Clean. Prod. 2013, 47, 141-148. [CrossRef]

10. Nishitani, K.; Kaneko, S.; Fujii, H.; Komatsu, S. Are firms' voluntary environmental management activities beneficial for the environment and business? An empirical study focusing on Japanese manufacturing firms. J. Environ. Manag. 2012, 105, 121-130. [CrossRef] [PubMed]

11. Yoon, H.S.; Kim, E.S.; Kim, M.S.; Lee, J.Y.; Lee, G.B.; Ahn, S.H. Towards greener machine tools-A review on energy saving strategies and technologies. Renew. Sustain. Energy Rev. 2015, 48, 870-891. [CrossRef]

12. Hu, S.; Liu, F.; He, Y.; Hu, T. An on-line approach for energy efficiency monitoring of machine tools. J. Clean. Prod. 2012, 27, 133-140. [CrossRef]

13. Avram, O.I.; Xirouchakis, P. Evaluating the use phase energy requirements of a machine tool system. J. Clean. Prod. 2011, 19, 699-711. [CrossRef]

14. Sreejith, P.S.; Ngoi, B.K.A. Dry machining: Machining of the future. J. Mater. Process. Technol. 2000, 101, 287-291. [CrossRef]

15. Pusavec, F.; Krajnik, P.; Kopac, J. Transitioning to sustainable production-Part I: Application on machining technologies. J. Clean. Prod. 2010, 18, 174-184. [CrossRef]

16. Pusavec, F.; Kramar, D.; Krajnik, P.; Kopac, J. Transitioning to sustainable production—Part II: Evaluation of sustainable machining technologies. J. Clean. Prod. 2010, 18, 1211-1221. [CrossRef]

17. Kalpakjian, S.; Schmid, S.R. Manufacturing Engineering and Technology, 7th ed.; Prentice Hall: Upper Saddle River, NJ, USA, 2013.

18. Alvarez, R.; Domingo, R.; Sebastian, M.A. The formation of saw toothed chip in a titanium alloy: Influence of constitutive models. Strojniski Vestn. J. Mech. Eng. 2011, 57, 739-749. [CrossRef]

19. Balazic, M.; Kopac, J. Machining of titanium alloy Ti-6Al-4V for biomedical applications. StrojniskiVestn. J. Mech. Eng. 2010, 56, 1-5.

20. Norgate, T.E.; Wellwood, G. The potential applications for titanium metal powder and their life cycle impacts. Jom 2006, 58, 58-63. [CrossRef]

21. Kundrak, J.; Mamalis, A.G.; Gyani, K.; Markopoulos, A. Environmentally friendly precision machining. Mater. Manuf. Process. 2006, 21, 29-37. [CrossRef]

22. Özel, T.; Sima, M.; Srivastava, A.K.; Kaftanoglu, B. Investigations on the effects of multi-layered coated inserts in machining Ti-6Al-4V alloy with experiments and finite element simulations. CIRP Ann. Manuf. Technol. 2010, 59, 77-82. [CrossRef]

23. Rajemi, M.F.; Mativenga, P.T.; Aramcharoen, A. Sustainable machining: Selection of optimum turning conditions based on minimum energy considerations. J. Clean. Prod. 2010, 18, 1059-1065. [CrossRef]

24. Balogun, V.A.; Mativenga, P.T. Modelling of direct energy requirements in mechanical machining processes. J. Clean. Prod. 2013, 41, 179-186. [CrossRef]

25. Peng, T.; Xu, X.; Wang, L. A novel energy demand modelling approach for CNC machining based on function blocks. J. Manuf. Syst. 2014, 33, 196-208. [CrossRef]

26. Iqbal, A.; Zhang, H.C.; Kong, L.L.; Hussain, G. A rule-based system for trade-off among energy consumption, tool life, and productivity in machining process. J. Intell. Manuf. 2013. [CrossRef] 
27. Schultheiss, F.; Zhou, J.; Gröntoft, E.; Stahl, J.E. Sustainable machining through increasing the cutting tool utilization. J. Clean. Prod. 2013, 59, 298-307. [CrossRef]

28. Mativenga, P.T.; Rajemi, M.F. Calculation of optimum cutting parameters based on minimum energy footprint. CIRP Ann. Manuf. Technol. 2011, 60, 149-152. [CrossRef]

29. Fang, K.; Uhan, N.; Zhao, F.; Sutherland, J.W. A new approach to scheduling in manufacturing for power consumption and carbon footprint reduction. J. Manuf. Syst. 2011, 30, 234-240. [CrossRef]

30. Yingjie, Z. Energy efficiency techniques in machining process: A review. Int. J. Adv. Manuf. Technol. 2014, 71, 1123-1132. [CrossRef]

31. Peng, T.; Xu, X. Energy-efficient machining systems: A critical review. Int. J. Adv. Manuf. Technol. 2014, 72, 1389-1406. [CrossRef]

32. Matweb. Material Propriety Data. Available online: http:/ /www.matweb.com (accessed on 15 May 2013 ).

33. International Organization for Standardization (ISO). ISO 1832:2012. Indexable Inserts for Cutting Tools_Designation, International Organization for Standardization; ISO: Geneva, Switzerland, 2012.

34. Klocke, F.; Döbbeler, B.; Binder, M.; Kramer, N.; Grüter, R.; Lung, D. Ecological evaluation of PVD and CVD coating systems in metal cutting processes assessed. In Proceedings of the 11th Global Conference on Sustainable Manufacturing-Innovative Solutions, Berlin, Germany, 23-25 September 2013; Seliger, G., Ed.; pp. 381-386.

35. Andriya, N.; Rao, P.V.; Ghosh, S. Dry machining of Ti-6Al-4V using PVD coated TiAlN tools. In Proceedings of the World Congress on Engineering, London, UK, 4-6 July 2012; pp. 1-6.

36. Prengel, H.G.; Jindal, P.C.; Wendt, K.H.; Santhanam, A.T.; Hegde, P.L.; Penich, R.M. A new class of high performance PVD coatings for carbide cutting tools. Surf. Coat. Technol. 2001, 139, 25-34. [CrossRef]

37. Jaffery, S.I.; Mativenga, P.T. Assessment of the machinability of Ti-6Al-4V alloy using the wear map approach. Int. J. Adv. Manuf. Technol. 2009, 40, 687-696. [CrossRef]

38. Dahmus, J.B.; Gutowski, T.G. An environmental analysis of machining. In Proceedings of the American Society of Mechanical Engineers (ASME) International Mechanical Engineering Congress, Anaheim, CA, USA, 13-19 November 2004; pp. 1-10.

39. Sun, S.; Brandt, M.; Mo, P.T.M. Evolution of tool wear and its effect on cutting forces during dry machining of Ti-6Al-4V alloy. Proc. Inst. Mech. Eng. BJ. Eng. Manuf. 2014, 228, 191-202. [CrossRef]

40. Red Eléctrica Española (RED). Informe Mensual; Red Eléctrica Española (RED): Alcobendas, Madrid, Spain, 2014.

41. Intergovernmental Panel on Climate Change. Volume 3: Industrial processes and product use, Chapter 4: Metal industry emissions. In IPCC Guidelines for National Greenhouse Gas Inventories; Eggleston, H.S., Buendia, L., Miwa, K., Ngara, T., Tanabe, K., Eds.; Institute for Global Environmental Strategies: Kanagawa, Japan, 2006.

42. Pré Consultants. SimaPro 8 Software; Pré Consultants: Amersfoort, The Netherlands, 2013.

43. International Organization for Standardization (ISO). ISO 3685:1993. Tool-Life Testing with Single-Point Turning Tools; ISO: Geneva, Switzerland, 1993.

44. Taguchi, G. Introduction to Quality Engineering; Asian Productivity Organization: Tokyo, Japan, 1990.

45. Kopac, J.; Bahor, M.; Sokovic, M. Optimal machining parameters for achieving the desired surface roughness in fine turning of cold pre-formed steel workpieces. Int. J. Mach. Tools Manuf. 2002, 42, 707-716. [CrossRef]

46. Motorcu, A.R. The optimization of machining parameters using the Taguchi method for surface roughness of AISI 8660 hardened alloy steel. StrojniskiVestn. J. Mech. Eng. 2010, 56, 391-401.

47. Montgomery, D.C. Design and Analysis of Experiments, 5th ed.; John Wiley \& Sons Inc.: Hoboken, NJ, USA, 2001.

48. Statgraphics. Available online: http://www.statgraphics.com/ (accessed on 22 September 2014).

49. Bhushan, R.K. Optimization of cutting parameters for minimizing power consumption and maximizing tool life during machining of $\mathrm{Al}$ alloy SiC particle composites. J. Clean. Prod. 2013, 39, 242-254. [CrossRef]

(C) 2015 by the authors; licensee MDPI, Basel, Switzerland. This article is an open access article distributed under the terms and conditions of the Creative Commons by Attribution (CC-BY) license (http://creativecommons.org/licenses/by/4.0/). 